\title{
On the Cultivation of the Core Socialist Values in Higher Vocational Colleges
}

\author{
Liu Jiqiang ${ }^{1, a, *}$ Cai Zhiqing ${ }^{2, b}$ \\ 1,2 Sichuan College of Architecture Technology, Deyang 618000, China \\ a514698053@qq.com, b906122546@qq.com \\ *Liu Jiqiang
}

Keywords: Higher vocational colleges, Core socialist values, Cultivation, Path.

\begin{abstract}
The concept that the core socialist values must be vigorously cultivated and practiced has been formed. Higher vocational college students are an important reserve force in the national construction and service, and their growth and values will affect the future construction and development of the country. Higher vocational colleges should cultivate and practice the core socialist values for the students in various aspects, such as the classroom teaching, social practice, campus culture construction, and so on.
\end{abstract}

\section{Introduction}

The concept that the core socialist values must be vigorously cultivated and practiced has been formed. Higher vocational college students are an important reserve force in the national construction, management and service. They are in the critical period of values formation, and their values will influence the future construction and development of the country. Under the new situation, higher vocational colleges should further strengthen and improve the education of the core socialist values.

\section{On the three "musts" of cultivating the core socialist values in colleges}

\subsection{Must grasp the richness of the core socialist values and stress the effectiveness of education}

The core socialist values are prosperity, democracy, civility, harmony, freedom, equality, justice, the rule of law, patriotism, dedication, integrity, and friendship. Whether it is to construct a prosperous, democratic, civilized and harmonious country, or to establish a freedom society as equality, justice, and rule of law, all needs to do personal patriotism, dedication, integrity and friendliness. The three aspects are a complete unity.

The core socialist values in the rich connotation of national, social and personal level, not only direct the development of the higher vocational students' demands, but also point out the direction of the objectives and requirements of the education in higher vocational colleges.

The gradation and richness of the core socialist values, as well as the diversity of individual development and the complexity of individual differences, has raised the demand for improving the effectiveness of education. Education in higher vocational colleges should be based on the correct analysis of the current higher vocational students' ideological trends, knowledge level, awareness of emotional and psychological state.

\subsection{Must face the contradiction between the long-term formation of individual values and the shorter time of higher vocational education}

Values are the standard of individual's right judgment and choice, and also the criterion of individual value judgment. The formation and establishment of a person's value needs his value cognition and inner identity for a longer period of time. The individual needs to internalize the external demand for its concept of consciousness, the concept of individual needs will be internalized externalized as specific behavior. In terms of the process of individual value internalization and identity, it is 
necessary for individuals to experience the input of external ideas, through the individual's acceptance and absorption of ideas, and then to the process of individual identification of values. In addition, it must be clear that because of the complexity of education and individual differences, the cultivation and establishment of individual good habits or positive values cannot be immediate. All of these confirm the long-term nature of the formation of individual values. The "contrast" is that the higher vocational students learning time is relatively short. The current higher vocational students' learning in colleges and internship time can be summarized as " $2+1$ ", " $2.5+0.5$ " or " $2.8+0.2$ " modes. " $2+1$ "indicates that there are two years of learning in colleges and one year internship in companies. " $2.5+0.5$ "means there are two and a half years of learning in colleges and internship for half a year. " $2.8+0.2$ " indicates there are nearly three years of college learning and about two months of internship in the sixth semester. Higher vocational students learning time are relatively short-lived reflects the urgency and difficulty of higher vocational college students' values education. The vocational colleges must highlight the core values education for students.

\subsection{Must face the contradiction between the diversification of values in today's society and the immaturity of higher vocational students' values}

Nowadays, it is an indisputable fact that the environment of the individual values of higher vocational college students is complicated. In the past forty years since China's reform and opening up, the economic and social development has made great achievements that have amazed the whole world. However, in the influence of political pluralism and economic globalization, especially the rapid development of global information. Internet without borders and with convenience, as well as other media, makes an unprecedented increase in value choice of openness, autonomy and freedom. To some extent, the tension and influence of our traditional values are weakened.

Higher vocational college students today are almost born after 1995. Many factors such as society and family, as well as their own mental development characteristics are contributed to the formation of their world outlook and life values. Higher vocational college students are affected by the social environment and cultural background. They are sunlight, lively, positive, as well as some of them are individualism, and the lack of sincerity.

The impact of the diversification of social values and values of higher vocational college students are not mature, that reflects the arduous and long-term of values education. The main melody of the vocational colleges must adhere to the core socialist values education.

\section{The basic path to cultivate the core socialist values in higher vocational colleges}

\subsection{Making full use of the classroom teaching}

Classroom teaching is the most important way to pass on the outstanding achievements of human culture and guide the students to get indirect experience and cognition. The purpose of education is to educate people, and the classroom teaching is the main channel. The public basic courses, professional foundation courses and professional core courses are taught by the classroom teaching. The purpose of teaching is to cultivate people. The core socialist values education should seize the key point of classroom teaching, and integrate it into the classroom teaching of various subjects and majors.

In these courses, we should pay special attention to the main channel function of ideological and political theory course. Relying on the college students' ideological and political theory course, situation and policy education, philosophy of social science courses and professional courses in higher vocational colleges, which can build a multi-level, three-dimensional, full range of view of the "first class" teaching system. At present, almost all vocational colleges attach great importance to combine the cultivation of core socialist values with the teaching of ideological and political theory courses. Higher vocational colleges should also deepen the connotation through strengthening the construction and teaching reform, promote students to the theory of internalization in the heart, from 
the knowledge receiving to belief and life experience, and ultimately to practice in the words and deeds.

Teachers are engineers of human souls. In classroom teaching, teachers should not be overlooked the exemplary role of morality education. Teachers in higher vocational colleges can not only do teaching well, but also have high moral standards, especially teachers' noble moral sentiments and rigorous attitude towards scholarly research, which exert a subtle influence on students' growth and development. Higher vocational colleges should adhere to the teachers in the classroom teaching ethics performance as the primary criteria of teacher evaluation. That will play an important role in boosting the cultivation and practice of students' core socialist values.

\subsection{Playing the basic role of campus culture infiltration}

Campus cultural environment has an important "infiltration" effect on regulating college students' words and deeds. Excellent cultural activities and beautiful cultural environment can highlight the concepts and characteristics of college running. It also annotates the history and tradition of the college. Higher vocational colleges should pay attention to the excavation of the buildings and landscaping. Spirit culture plays an important role in educating people. Higher vocational colleges should formulate and improve the campus behavior norms of students, and promote the regulation and guidance of the behavior culture. Higher vocational colleges should give full play to the importance of systematic, scientific and top-level design in the development planning of higher vocational colleges, and embody the institutional culture and the edification and infiltration of campus fashion formed by the style of teaching and the style of study. Higher vocational colleges should strengthen and improve the college website, the official micro-blog and WeChat and other official network culture construction. In the process of creating campus culture brand, higher vocational colleges should try to adhere to the campus arts and students' art performances, and pay attention to improving the aesthetic and humanistic qualities of the activities. A series of activities such as "Moral Forum" in some higher vocational colleges are beneficial attempts and effective methods to cultivate and practice the core socialist values.

\subsection{Highlight the externalization of social practice}

Social practice is the basic path of students' growth and political socialization in higher vocational colleges. The process of social practice will contribute to the core socialist values into quality, outside into action for the students. That can sublimate their understanding of core socialist values and externalization. Through social practice, students can not only increase their abilities, but also enhance their patriotic, professional and other good qualities. Higher vocational colleges should also make full use of more practical training, internships and other opportunities, exercise students' practical ability, and promote intelligent transformation. In order to meet the practical needs of students, students can carry out social experiential activities in specific moral practice activities. Higher vocational colleges can also carry out practical teaching activities, such as old revolutionary base areas, which can help students receive revolutionary spirit education and patriotism education. In the process of social practice, students should also pay attention to the combination of the actual new rural and urban communities, whatever the appropriate relevant professional volunteer service activities.

\subsection{Taking the unique advantages of important festivals}

Excellent traditional culture represents a unique national spiritual identity, which embodies the deepest spiritual pursuit of the nation. Especially the traditional festivals will not only allow people to memorize and strengthen the unique national or ethnic cultural value of the symbols, and their special cohesion and oriented to the student life or moral values education, but also have very important significance on students' mental health adjustment. National Day contains the spirit of patriotism and collectivism education. Spring Festival can let people's heart get settled, enhance the sense of social 
identity, and enhance the national cohesion. Higher vocational colleges should pay attention to the cultural and educational work of national traditional festivals and major festivals.

The ceremony of higher vocational colleges includes the school beginning ceremony, the awarding ceremony, and the graduation ceremony, and so on. The school beginning ceremony should focus on solving the problems of the students adapting to the environment, and on establishing their goals. For the awarding ceremony, should focus on praising the outstanding, encouraging more students to pursue the excellent and inspire a sense of achievement and sense of honor. The graduation ceremony should make the students know the thanks for the college, and serve the motherland hard in the future.

\subsection{Fully display the attraction and affinity of new media}

The rapid development of modern information technology and the rapid development of new media have changed people's study and life. The new media also makes "everyone has a microphone". "All are communicators" become a fact. Higher vocational colleges should pay attention to the construction and use of the new media. At present, higher vocational colleges should give full play to the advantages of convenient communication and interaction of the new media, and optimize the mode of interaction with students. Higher vocational colleges should set up the college official micro-blog and WeChat. First of all, higher vocational colleges should strengthen the contents construction of the official micro-blog and WeChat. In order to adapt higher vocational students to the rhythm of "short" and "fast", colleges can carry out "micro" series activities. Higher vocational colleges may invite social scholars and advanced models to carry out micro interviews. Higher vocational colleges can also carry out "micro" films and other activities. Which can stimulate the students deep thinking and promote their cognition, identity and practice of core socialist values in the educational activities that students like and are willing to participate in.

\section{Summary}

The core socialist values are the strong foundation of China. The higher vocational college students are at the crucial stage of shaping values. Higher vocational colleges must strengthen and improve the cultivation of the core socialist values through understanding the rich contents of the core socialist values well, highlighting the effectiveness of education and recognizing the particularities of education. Higher vocational colleges should help the students establish the correct ideals and beliefs, form the correct values, improve the comprehensive quality in the whole process of classroom teaching, social practice, campus culture, and so on.

\section{Acknowledgement}

This research was financially supported by the Ideological and Political Education Researching Association of Sichuan Province (Grant NO.SCSZ2017202, and Grant NO. SCSZ2017203) and Sichuan College of Architectural Technology (Grant NO.SCJY2016022 and NO.SCJY2016019).

\section{References}

[1] Du Yubo. To promote the innovating and developing of ideological and political education by deepening the cultivation of core socialist values, Ideological Education Research, 2015 (2).

[2] Zhang Shuihua. On the countermeasures of enhancing the effectiveness of ideological and political education with the diversification of college students' values, Hubei Social Sciences, $2011(9)$..

[3] Chang Yutong, Sun Zhiyong. On the path of college students practice the core socialist values. School Party Building and Ideological Education, 2015 (8). 